\title{
Recovering from the COVID-19 shock: the role of risk perception and perceived effectiveness of protective measures on travel intention during the pandemic
}

\author{
Joon Woo Yoo ${ }^{1}$ Junsung Park ${ }^{1}$ Jong Ho Lee ${ }^{1} \cdot$ Heejun Park ${ }^{1}$
}

Received: 29 April 2021 / Accepted: 22 December 2021 / Published online: 30 January 2022

() The Author(s), under exclusive licence to Springer-Verlag GmbH Germany, part of Springer Nature 2021

\begin{abstract}
The COVID-19 pandemic has caused severe damage to the global tourism industry. However, there is hope that the industry will recover in the near future. This study investigates how the pandemic has affected the peoples' traveling intention and provide implications for accelerating the recovery of the industry. A PLS-SEM analysis of 382 samples confirms the significant effect of COVID-19 risk perception on travel intention while also highlighting the mediating role of perceived effectiveness of COVID-19 protective measures. The study also concludes that there is a significant difference in the perceived protective measure effectiveness-travel intention relation based on accommodation preference.
\end{abstract}

Keywords COVID-19 Policy effectiveness $\cdot$ Social distancing $\cdot$ Accommodation type $\cdot$ Risk perception

\section{Introduction}

The Coronavirus disease 2019 (COVID-19) has caused unprecedented damage to the global tourism industry (Bakar and Rosbi 2020). Due to travel bans and mandatory quarantine, international tourist arrivals dropped a staggering 74\% worldwide in 2020 compared to the previous year (Das and Tiwari 2020; UNWTO 2021). According to the United Nations World Tourism Organization's (UNWTO) 2021 report, international tourism plunged to the levels of 30 years ago, with an estimated US\$1.3 trillion loss in export revenues from international tourism and over 100 million tourism-related jobs at risk. On the bright side, however, with the development of vaccines and medication for treatment, there is hope that travel demand will gradually recover in the near future (Zhang et al. 2021).

\section{Heejun Park}

h.park@yonsei.ac.kr

1 Department of Industrial Engineering, Yonsei University, 50, Yonsei-ro, Seodaemun-gu, Seoul, Korea 
The pandemic shock on tourism has caught the attention of numerous studies, analyzing the depth and severity of the pandemic shock on the industry (Hoang et al. 2021; Uğur and Akbıyık 2020; Shin et al. 2021). However, studies focusing on the recovery from the pandemic remain limited (Assaf and Scuderi 2020). In one of the few limited studies on tourism recovery, Zhang et al. (2021) stated that a majority of experts agreed that tourist arrivals reached a minimum in 2020Q2 and would recover to baseline by the end of 2021. The results of Zhang et al. (2021) and other similar studies, however, are insufficient to explain how visitors can be attracted during or after the pandemic, particularly since the pandemic has precipitated dramatic changes in people's perceptions and behavior regarding personal safety (Cori et al. 2020).

Another topic that has gained significant interest during the pandemic is the COVID-19 protective measures and how the perceived effectiveness of these measures differs between individuals (Meier et al. 2020). Protective measures, such as sanitization and social distancing, significantly changed how people act during the pandemic. For example, Margraf et al. (2021) and Nakayachi et al. (2021) found that the perceived effectiveness of COVID-19 protective measures differs significantly between countries and between the public and medical experts. However, simply comparing the differences between perceived effectiveness is insufficient in explaining how these differences affect individual behavior during and after the pandemic. Furthermore, despite its importance, the role of these protective measures in the tourism industry has yet been investigated.

To overcome the limitations of prior studies, this study investigates how the COVID19 pandemic has altered travel intention, in particular how people's risk perception of COVID-19 affects travel intention and if the perceived effectiveness of COVID-19 protective measures affects this relationship. Although it is established that risk perception is a critical factor in explaining behavioral intention in numerous contexts, studies on how it affects travel intention during a pandemic remain limited. Our study aims to fill this research gap and provide meaningful theoretical and managerial implications.

The results and implications of our study contribute significantly to both researchers and practitioners in the tourism industry. The pandemic has drastically changed the peoples' priorities about health and safety and with more and more countries allowing overseas travel, a timely study on how the industry should respond and evolve is needed. By investigating how COVID-19 has changed the perception and standards for post-pandemic travel and how it affects travel intention, our study provides guidelines on how the tourism industry should transform in the post-pandemic era. Furthermore, by adopting the perceived effectiveness of COVID-19 protective measures, which is a crucial but rather unexplored concept in COVID-19 literature, we provide implications for researchers aiming to investigate individual behavior during or after the pandemic.

\section{Literature review and hypotheses}

The following section provides a review of the literature on risk perception, perceived effectiveness of COVID-19 protective measures, and their relationship to travel intention. Then, we present our hypotheses and research model based on the literature review and the results of prior studies. 


\subsection{COVID-19 risk perception as an antecedent of travel intention}

\subsubsection{Risk perception}

Risk perception is defined as an individual's evaluation of the likelihood and consequences of a threatening event, such as the COVID-19 pandemic (Cori et al. 2020). Prior studies confirm that risk perception significantly influences a person's attitude and behavior (Brewer et al. 2007; Chatterjee et al. 2020; Zeballos Rivas et al. 2021). Zeballos Rivas et al. (2021) found that exposure to COVID-19-related information on social media affected people's risk perception of COVID-19, which positively affected their preventive attitudes and behaviors, as well as their attitudes to vaccines. Similarly, other studies found that risk perception has a significant effect on behavior, from everyday behaviors such as shopping, to more specific acts such as anti-nuclear behavior (Safón and Escribá-Esteve 2011; Zhu et al. 2016).

According to Liang and Xue (2009) and Chatterjee et al. (2020), an individual's risk perception can be measured through two main constructs: perceived threat, which is further divided into perceived severity and perceived susceptibility, and perceived avoidability. Perceived threat is defined as the degree to which an individual perceives a certain threat to be harmful to their well-being (Liang and Xue 2009). Normally, a higher perceived threat of a certain event results in a higher likelihood of an individual pursuing protective behavior or refraining from risktaking behavior. Vacondio et al. (2021) found that the perceived threat of COVID19 positively influences self-protective behavior, such as mask wearing and hand washing. Conversely, Banks et al. (2010) concluded that perceived threat negatively affects risk-taking behavior on online social media, such as the sharing of personal information.

The second construct of risk perception, perceived avoidability, is defined as the individual's assessment of the likelihood that they will be able to avoid or prevent a threatening situation by taking preventive measures (Liang and Xue 2009). According to Liang et al. (2019), if an individual believes that a certain threat is avoidable, or that they have control of the situation, they are less likely to engage in any defense mechanisms. The results of Katapodi et al. (2009) also support this claim by showing that women with high perceived avoidability of breast cancer showed lower breast-cancer-screening behavior.

Due to the COVID-19 pandemic, the concept of risk perception has become particularly important in studying behavioral intention (Cori et al. 2020). As a result, several studies analyzed the effect of COVID-19 risk perception and its effect on pandemic-related behavior. For example, by expanding the widely used theory of planned behavior, Long and Khoi (2020) found that increased risk perception of consumers led them to hoard food during the COVID-19 pandemic. Similarly, Hakim et al. (2021) concluded that the perceived risk of individuals significantly affected their intention to visit restaurants during the pandemic. 


\subsubsection{COVID-19 risk perception and travel intention}

Studies on risk perception in the tourism context have found that risk perception is highly related to one's travel intention, travel destination choice, and destination avoidance (Coshall 2003; Floyd et al. 2000; Neuburger and Egger 2020). Specifically, Sönmez and Graefe (1998) concluded that perceived risk is a significant predictor of both revisit intention and destination avoidance. Similarly, in a study conducted after the September 11, 2001 terror attacks, Floyd et al. (2004) found that individuals who did not consider safety to be an important factor in travel decisions, or individuals with lower levels of perceived risk, were more likely to travel in the following year.

However, because risk perception is comprised of two conceptually contrasting, yet complementary constructs, perceived threat and avoidability, treating it as a single construct could lead to incomplete understanding on the effects of risk perception on travel intention (Liang et al. 2019). Since both these constructs have different impacts on an individual's behavioral intention (Liang and Xue 2009; Liang et al. 2019), comparing their effect on travel intention could provide meaningful implications to the tourism industry hoping to recover from the pandemic.

As mentioned earlier, individuals with higher levels of perceived threat, both perceived severity and susceptibility, are more likely to refrain from risk-taking behavior, which, in this context, is travelling during the COVID-19 pandemic. For example, McKercher and Chon (2004) claimed that the abnormally high level of perceived threat, or "over-reaction", regarding the severe acute respiratory syndrome (SARS) outbreak led to a staggering $70 \%$ decline in tourist arrivals in Asia. Meng et al. (2021) also confirmed that COVID-19 risk perception significantly affects people's travel intention of Chinese leisure travelers. Therefore, it could be inferred that higher levels of perceived threat from COVID-19 will have a negative effect on travel intention.

Perceived avoidability, meanwhile, is a relatively new concept in the tourism literature. However, its effect on travel intention can be inferred through related studies from different contexts. Romer and Jamieson (2001) found that young smokers aged 14-22 years old tended to underestimate the likelihood of smoking-related death and the fatality of lung cancer. Therefore, if an individual perceives COVID-19 to be preventable or avoidable, they are more likely to engage in behaviors with higher risk, such as travelling. Thus, we hypothesize that higher levels of perceived avoidability of COVID-19 will have a positive effect on travel intention. Therefore, our hypotheses are as follows:

H1(a) Perceived severity of COVID-19 has a negative effect on travel intention.

H1(b) Perceived susceptibility to COVID-19 has a negative effect on travel intention.

H2 Perceived avoidability of COVID-19 has a positive effect on travel intention. 


\subsection{The mediating role of the perceived effectiveness of COVID-19 protective measures in the risk perception-travel intention relationship}

\subsubsection{COVID-19 risk perception and perceived effectiveness of COVID-19 protective measures}

Perceived policy effectiveness is defined as an individual's perception, both favorable and unfavorable, toward a specific policy measure (Wan et al. 2014). The literature indicates that an individual's risk perception toward a certain event significantly affects their attitude or perception toward protective measures (Zeballos Rivas et al. 2021). In a study focusing on increasing the effectiveness of anti-speeding messages, Cauberghe et al. (2009) found that the risk perception of speeding while driving significantly affects anti-speeding attitude and intention.

During the COVID-19 pandemic, several protective measures were adopted to stop the rapid spread of the virus and promote public health. The Korean Ministry of Health and Welfare, for example, promoted the following COVID-19 protective measures: (a) sanitization of public spaces; (b) social distancing of at least two meters; (c) meetings of four or fewer people; (d) shutdown of multiuse facilities (e.g., fitness centers, bars, restaurants). Although studies investigating the direct effect of COVID-19 risk perception on the effectiveness of these measures are still lacking, Prasetyo et al. (2020) found that the perceived severity and vulnerability of individuals affect their perceived behavioral control, subjective norms, and attitude toward COVID-19 prevention measures, which subsequently affected intention to follow and perceived effectiveness. Furthermore, studies focusing on COVID-19 vaccine acceptance confirm that people's risk perception of COVID-19 positively affects their perceived effectiveness toward vaccines (Doornekamp et al. 2020; Zeballos Rivas et al. 2021).

Specifically, in the case of perceived avoidability, Liang et al. (2019) and Liang and Xue (2009) claim that the more individuals feel that a certain threat is either controllable or avoidable, the more effective they will perceive the safeguarding measures to be, and thus will be motivated to execute these measures. On the other hand, if individuals feel that the threat is unavoidable, regardless of their effort, they are more likely to perceive the safeguarding measures as ineffective and are less likely to adopt these measures. Similarly, Prasetyo et al. (2020) found that perceived vulnerability, which is an opposing construct of perceived avoidability, negatively affects an individual's perceived behavioral control toward COVID-19 protective measures, which is critical in increasing the perceived effectiveness of these measures. Thus, it could be inferred that perceived avoidability, on the other hand, would have a positive effect on the perceived effectiveness of COVID-19 protective measures.

However, no studies have yet examined the relation between an individual's perception toward COVID-19, COVID-19 protective measures, and travel intention. Therefore, to fill this research gap based on the results of studies supporting the positive relationship between risk perception and perception toward risk preventive measures, we hypothesize that there is a direct and positive relationship 
between COVID-19 risk perception, both perceived threat and avoidability, and perceived effectiveness of COVID-19 protective measures.

H3(a) Perceived severity of COVID-19 has a positive effect on perceived effectiveness of COVID-19 protective measures.

H3(b) Perceived susceptibility to COVID-19 has a positive effect on perceived effectiveness of COVID-19 protective measures.

H4 Perceived avoidability of COVID-19 has a positive effect on perceived effectiveness of COVID-19 protective measures.

\subsubsection{Perceived effectiveness of COVID-19 protective measures and travel intention}

Previous studies show that perceived policy effectiveness significantly affects behavioral intention (Michie et al. 2011). Schneider and Ingram (1990) claimed that by manipulating symbols and influencing values, public policies could alter people's beliefs or attitudes, thus leading to behavioral changes. Similarly, Michie et al. (2011) proposed the COM-B (Capability, Opportunity, Motivation-Behavior) model, claiming that behavioral change in compliance with public policies is influenced by factors such as attitudes, beliefs, and cost-benefit analysis. In a more specific context, Wan et al. (2014) found that perceived effectiveness of policy measures significantly affected the public's behavioral intention to recycle. However, as Wan et al. (2014) stated, research on how perceived policy effectiveness motivates people to engage in certain behaviors is still lacking.

Furthermore, since the tourism industry has not faced a global crisis as devastating as the COVID-19 pandemic, research on the relationship between policy effectiveness and travel intention is limited. Using a Bayesian approach to understand the travel intention of Indian travelers during the pandemic, Das and Tiwari (2020) concluded that their willingness to adopt non-pharmaceutical interventions, such as wearing masks, significantly affected travel intention. Our study aims to extend the results of Das and Tiwari (2020) based on prior studies finding that individuals are more willing to participate in preventive interventions if the perceived effectiveness of the intervention is high (Bashirian et al. 2020; Ezati Rad et al. 2021). Therefore, we hypothesize that there will be a positive relationship between perceived effectiveness of COVID-19 protective measures and travel intention during the pandemic.

H5 Perceived effectiveness of COVID-19 protective measures has a positive effect on travel intention.

\subsubsection{The mediating role of perceived effectiveness of COVID-19 protective measures}

Studies investigating the relation between risk perception and travel intention have found that, while risk perception is a critical antecedent of travel intention, this 
relation is often mediated by other factors depending on the context. For example, Nazir et al. (2021) analyzed the mediating role of destination image on the risk perception-travel intention relation, concluding that while perceived risk and constraint negatively affect travel intention, a positive destination image can overcome the risks and constraints of certain tourist destinations. Similarly, in a study on the travel intention of tourists after the 2011 Fukushima disaster, Chew and Jahari (2014) found that both cognitive and affective image significantly mediates the relation between socio-psychological risk, financial risk, and intention to revisit. Recently in the COVID-19 context, Meng et al. (2021) concluded that interpersonal communication, media communication, and COVID-19 related knowledge act as an important mediator on the risk perception-travel intention relation of Chinese tourists during the pandemic.

As mentioned in Sects. 2.2.1 and 2.2.2, prior studies confirm that the perceived effectiveness of COVID-19 protective measures has a significant relation between both risk perception and travel intention. However, studies have yet investigated its role as a mediating variable between the two constructs. Considering that COVID19 preventive measures have had a large impact on individual behavior, understanding how the peoples' perception of these policies mediate the risk perception-travel intention relation could provide significant implications to both practitioners and researchers. Thus, based on the results of prior studies and our hypotheses regarding the COVID-19 risk perception, perceived effectiveness of protective measures, and travel intention relation, the following hypothesis is presented.

H6 Perceived effectiveness of COVID-19 protective measures mediates the relation between COVID-19 risk perception and travel intention.

\subsection{The moderating role of accommodation type in the perceived effectiveness of COVID-19 protective measures-travel intention relationship}

Prior studies on the topic of accommodation choice prove that different accommodation types provide different advantages and, thus, should target different customer segments (Birinci et al. 2018; Song et al. 2020; Yan et al. 2019). Yavas and Babakus (2005) classified hotel attributes into five main factors: general amenities, convenience, core service, room amenities, and ambiance. Consequently, they found that hotel users consider general amenities and core service as the main attributes when choosing hotels. Meanwhile, Cheng and Jin (2019) concluded that the key attributes of Airbnb properties are location, amenities, and the host. Furthermore, they state that Airbnb's strength compared to hotels is that they are able to provide unique local experiences (Cheng and Jin 2019).

The COVID-19 pandemic, however, has significantly changed people's accommodation choice criteria (Bresciani et al. 2021; Pappas and Glyptou 2021). A major difference between hotels and Airbnb facilities is that hotels require customers to share public spaces, such as the lobby or restaurants, while Airbnb facilities, with the exception of shared rooms, allow customers to use the entire flat without any contact with other people. This difference is of particular significance during the pandemic because 
people are reluctant to visit crowded places, such as hotel restaurants or lobbies. Bresciani et al. (2021) support this claim by concluding that while tourists are reluctant to book shared rooms on Airbnb during the pandemic, they prefer full flats over hotel rooms because they allow for social distancing. Furthermore, the study concluded that the need for physical distancing decreased the likelihood of choosing a hotel compared to choosing an entire flat on Airbnb.

On the other hand, hotels, compared to Airbnb, provide more professional services and follows strict hospitality standards (Birinci et al. 2018). According to Birinci et al. (2018) and Hoang et al. (2021), hotels have highly trained professionals who follow standard operating procedures. These services allow hotels to provide a more professional approach when dealing with the pandemic. For example, most major hotels provide sanitization and disinfection programs (ex. Hilton Cleanstay, Marriott Cleanliness Council) to create a safer environment for their guests.

Extending the results of the Bresciani et al. (2021) and Birinci et al. (2018), we infer that accommodation type (Hotel/Airbnb) could play a moderating role on the relation between the perceived effectiveness of COVID-19 protective measures and travel intention. For example, because Airbnb flats allow for easier social distancing and provides most of their service through their mobile application, customers who prefer to use Airbnb over hotels may show a stronger positive relation between the perceived effectiveness of COVID-19 protective measures and travel intention. Similarly, because hotels follow a stricter standard compared to Airbnb facilities, customers who prefer to use hotels may show a stronger effectiveness-travel intention relation.

While studies show that accommodation type moderates individual behavior in the tourism context (Song et al. 2020; Chan and Tung 2019), studies considering the effect of accommodation type during the pandemic is still limited. Under the assumption that perceived policy effectiveness significantly affects travel intention, observing how accommodation type moderates this relation could provide implications on how specific customer segments can be targeted as travel demand begins to increase.

Therefore, we wish to observe if there is a significant difference between the perceived effectiveness of COVID-19 protective measures based on accommodation preference. Furthermore, in order to prevent any confusion and provide a clear division between hotels and Airbnb flats, we limited the room type of Airbnb to full flats only.

H7 Accommodation type moderates the relation between perceived effectiveness of COVID-19 protective measures and travel intention.

Thus, based on our hypotheses built on the results of prior studies, our research model is presented in Fig. 1. 


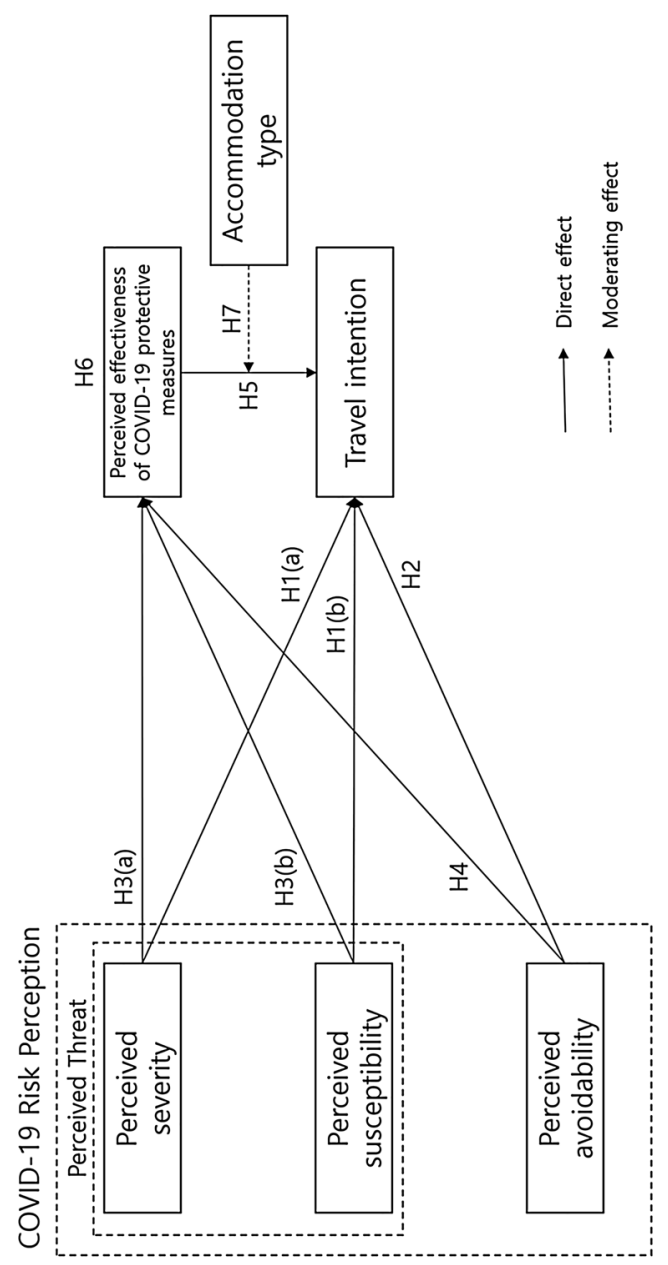




\section{Methodology}

\subsection{Survey items}

We adopted survey items from studies related to travel intention, risk perception, and policy effectiveness and modified them to fit our research context. Travel intention was measured using three items from Lee et al. (2012). The two constructs of perceived threat, that is, perceived severity and perceived susceptibility, were measured using items from Luo et al. (2021) and Prasetyo et al. (2020), respectively. Perceived avoidability was measured using three items from Liang et al. (2019), and the four items for measuring the perceived effectiveness of COVID-19 protective measures, which is the only formative construct in our measurement model, were adopted from Franzen and Wöhner (2021). The measurement items were revised through a pilot test to ensure content validity, and items that did not meet the validity criteria were deleted in the final survey. All items were measured based on a 5-point Likert scale, ranging from 1 for "strongly disagree" to 5 for "strongly agree." The survey items are presented in Table 1.

Additionally, because the survey was conducted in Korea, a double translation (English-Korean-English) was conducted. Furthermore, prior to the main survey, a pilot survey was carried out on 5 samples to test for validity of the survey and check if there were any vague expressions within the questionnaire.

\subsection{Sampling and data collection}

To gather the data needed for the study, an online survey was distributed and collected via an online research company, Macromill Embrain. The survey was conducted from April 6-9, 2021 and was targeted at those over the age of 20 and living in South Korea. After eliminating surveys with insincere or incomplete responses, a total of 382 samples were used for the final analysis. The demographic characteristics of the respondents are presented in Table 2.

\section{Results}

We conducted a partial least squares structural equation modelling (PLS-SEM) using the SmartPLS 3.0. We specifically chose the PLS-SEM method rather than the CB-SEM method because the Perceived Effectiveness of COVID-19 Protective Measures construct is a formatively measured construct. Hair et al. (2019) states that when the model includes one or more formatively measured construct, the PLS is a more appropriate SEM method. Additionally, the PLS-SEM has advantages over traditional analysis methods because it allows for the assessment of measurement error and can predict latent variables using observed variables. Also, it effectively analyzes the causal relationship between several complex variables (Hair et al. 2017). Furthermore, the PLS-SEM has higher robustness when data are non-normal, which 


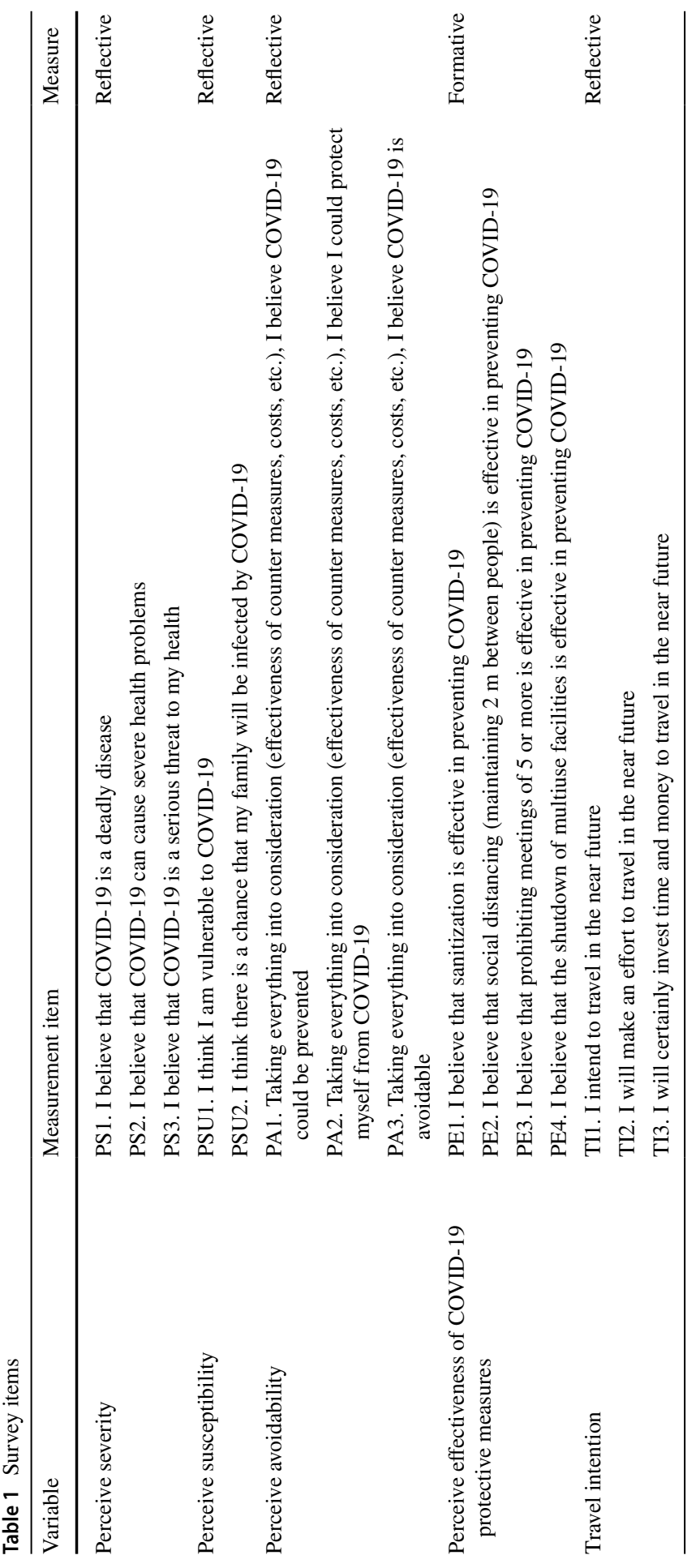


Table 2 Demographic characteristics

\begin{tabular}{|c|c|c|}
\hline Classification & Frequency $(N=382)$ & Percentage $(\%)$ \\
\hline \multicolumn{3}{|l|}{ Gender } \\
\hline Male & 168 & 44.0 \\
\hline Female & 214 & 56.0 \\
\hline \multicolumn{3}{|l|}{ Age } \\
\hline $20 \mathrm{~s}$ & 79 & 20.7 \\
\hline $30 \mathrm{~s}$ & 76 & 19.9 \\
\hline $40 \mathrm{~s}$ & 77 & 20.2 \\
\hline $50 \mathrm{~s}$ & 75 & 19.6 \\
\hline 60 and over & 75 & 19.6 \\
\hline \multicolumn{3}{|l|}{ Marital status } \\
\hline Single & 158 & 41.4 \\
\hline Married & 216 & 56.5 \\
\hline Other & 8 & 2.1 \\
\hline \multicolumn{3}{|l|}{ Educational level } \\
\hline Less than high school & 3 & 0.8 \\
\hline High school diploma & 66 & 17.3 \\
\hline Attending university & 23 & 6.0 \\
\hline Bachelor's degree & 249 & 65.2 \\
\hline Attending graduate school & 2 & 0.5 \\
\hline Master's degree/PhD & 39 & 10.2 \\
\hline \multicolumn{3}{|c|}{ Main source of COVID-19-related news/information } \\
\hline Television & 214 & 56.0 \\
\hline Social media (YouTube, Facebook, etc.) & 88 & 23.0 \\
\hline Government reports & 71 & 18.6 \\
\hline Friends/family & 9 & 2.4 \\
\hline \multicolumn{3}{|l|}{ Accommodation preference } \\
\hline Hotel & 212 & 55.5 \\
\hline Airbnb (full flat) & 170 & 44.5 \\
\hline
\end{tabular}

is the case for most survey-based data. The CB-SEM method on the other hand, could result in abnormal results when the data set size is limited (Hair et al. 2019; Reinartz et al. 2009; Hassan et al. 2015).

\subsection{Measurement model testing}

Prior to the hypotheses testing, we verified the validity of the measurement items. According to Hair et al. (2019), reflectively measured constructs and formatively measured constructs require different metrics to be applied to test for validity.

For reflective measurement models, (1) the factor loadings of the survey items exceed $0.7,(2)$ the average variance extracted (AVE) of the constructs exceeds 0.5 , and (3) the composite reliability (CR) and Cronbach's alpha exceed 0.7 (Fornell and 
Table 3 Validity results of reflective constructs (factor loadings, AVE, CR, Cronbach's $\alpha$ )

\begin{tabular}{lllll}
\hline Variable & Factor loadings & AVE & CR & Cronbach's $\alpha$ \\
\hline Perceived severity & $0.860,0.913,0.905$ & 0.797 & 0.922 & 0.873 \\
Perceived susceptibility & $0.974,0.930$ & 0.907 & 0.951 & 0.902 \\
Perceived avoidability & $0.845,0.880,0.806$ & 0.713 & 0.881 & 0.798 \\
Travel intention & $0.910,0.885,0.940$ & 0.832 & 0.937 & 0.899 \\
\hline
\end{tabular}

Table 4 Discriminant validity results (HTMT)

\begin{tabular}{lllll}
\hline & PS & PSU & PA & TI \\
\hline PS & & & & \\
PSU & 0.403 & & & \\
PA & 0.045 & 0.195 & & \\
TI & 0.224 & 0.155 & 0.249 & \\
\hline
\end{tabular}

$P S$ perceived severity, $P S U$ perceived susceptibility, $P A$ perceived avoidability, $T I$ travel intention

Larcker 1981; Hair et al. 2019; Diamantopoulos and Siguaw 2006). Furthermore, discriminant validity is confirmed if the HTMT is lower than 0.9 (Hair et al. 2019). As shown in Tables 3 and 4, the results of the measurement testing of reflective constructs meet the required criteria.

In the case of formative measurement models, (1) the correlation between the formative construct and a single-item construct measuring the same concept should exceed 0.7 (redundancy analysis), (2) VIF lower than 3 is ideal while VIF $>3-5$ is acceptable, and (3) the statistical significance of weights must be significant at the $p$ value $<0.05$ level. However, if the factor loading exceeds 0.5 and is statistically significant, the indicator should not be removed even when the weight is insignificant (Hair et al. 2019; Diamantopoulos and Siguaw 2006). This is because in the case of formative measurement models, the indicator's contribution to the construct is relatively more important compared to its significance. Unlike reflective measurement models, removing a single formative indicator could negatively affect the measurement model's content validity, and thus should seldom be removed (Hair et al. 2019, 2021). Therefore, as shown in Table 5, while the weights of PE3 and PE4 were statistically insignificant, their item loading is above 0.5 and is statistically significant, and thus, were included in our model. Also, the result of the redundancy analysis showed that the correlation between the perceived effectiveness of COVID-19 protective measures and a single-item construct "overall, I believe that the COVID-19 protective measures are effective in preventing COVID-19" was 0.884, which is higher than the required criteria of 0.7 (Cheah et al. 2018; Hair et al. 2019). Finally, as shown in Table 6, the VIF value regarding the collinearity tests were below 3, confirming that collinearity is not an issue.

Furthermore, Henseler et al. (2016) states that, group comparisons using a moderator or multigroup analysis using SEM could often be misleading unless measurement invariance between the groups are established. Since our study aims to observe 


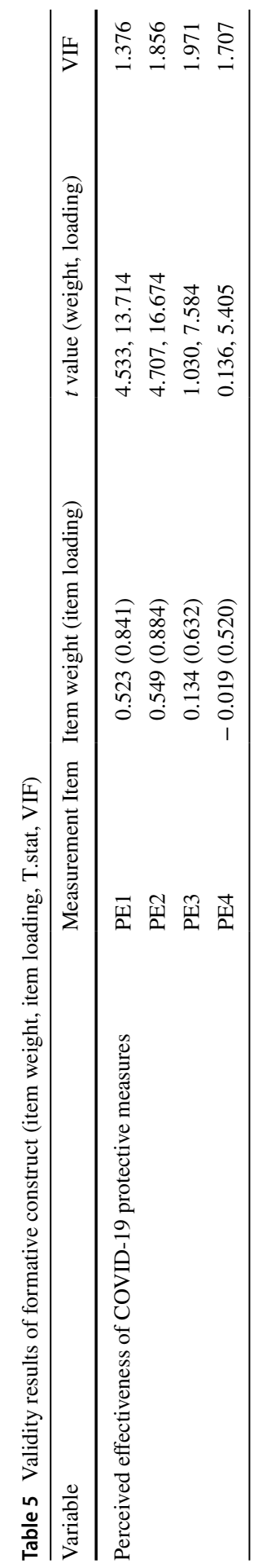


Table 6 Validity results of collinearity test (VIF)

\begin{tabular}{llc}
\hline Variable & $\begin{array}{l}\text { Perceived effectiveness of COVID-19 } \\
\text { protective measures }\end{array}$ & Travel intention \\
\hline Perceived severity & 1.146 & 1.178 \\
Perceived susceptibility & 1.178 & 1.189 \\
Perceived avoidability & 1.029 & 1.318 \\
Perceived effectiveness of COVID-19 & & 1.311 \\
$\quad$ protective measures & & \\
\hline
\end{tabular}

how accommodation type moderates the relation between perceived effectiveness of COVID-19 protective measures and travel intention, confirming the measurement invariance between these groups must be preceded to provide meaningful findings. Thus, the MICOM procedure, which is a three-step procedure confirming the configural, compositional invariance and the equality of composite mean values and variances, was conducted (Henseler et al. 2016). The results of the MICOM procedure, presented tin Table 7, show that all the criteria for step 1, 2, and 3 were met, indicating full measurement invariance.

\subsection{Structural model and hypotheses testing}

After confirming the validity of our measurement model, we tested the validity of our structural model and hypotheses (H1-7) using the PLS-SEM method. The

Table 7 Micom procedure results

\begin{tabular}{|c|c|c|c|c|c|}
\hline \multirow[t]{2}{*}{ Constructs } & \multirow{2}{*}{\multicolumn{2}{|c|}{$\begin{array}{l}\text { Configural invariance } \\
\text { (step 1) }\end{array}$}} & \multicolumn{3}{|c|}{ Compositional invariance (step 2) } \\
\hline & & & $C=1$ & CI & PMI \\
\hline PS & \multicolumn{2}{|c|}{ Yes } & 0.997 & {$[0.993,1.000]$} & Yes \\
\hline PSU & \multicolumn{2}{|c|}{ Yes } & 0.989 & {$[0.979,1.000]$} & Yes \\
\hline PA & \multicolumn{2}{|c|}{ Yes } & 0.998 & {$[0.994,1.000]$} & Yes \\
\hline $\mathrm{PE}$ & \multicolumn{2}{|c|}{ Yes } & 0.859 & {$[0.838,1.000]$} & Yes \\
\hline $\mathrm{TI}$ & \multicolumn{2}{|c|}{ Yes } & 0.998 & {$[0.993,1.000]$} & Yes \\
\hline \multirow[t]{2}{*}{ Constructs } & \multicolumn{5}{|c|}{ Equal mean values and variances (step 3 ) } \\
\hline & Mean dif. & $\mathrm{CI}$ & Variance dif. & $\mathrm{CI}$ & FMI \\
\hline PS & -0.072 & {$[-0.206,0.202]$} & 0.108 & {$[-0.309,0.322]$} & Yes \\
\hline PSU & -0.186 & {$[-0.204,0.205]$} & 0.002 & {$[-0.296,0.302]$} & Yes \\
\hline PA & -0.024 & {$[-0.203,0.199]$} & -0.037 & {$[-0.310,0.335]$} & Yes \\
\hline $\mathrm{PE}$ & -0.042 & {$[-0.205,0.204]$} & 0.094 & {$[-0.378,0.370]$} & Yes \\
\hline $\mathrm{TI}$ & -0.023 & {$[-0.207,0.207]$} & 0.151 & {$[-0.263,0.277]$} & Yes \\
\hline
\end{tabular}

$P S$ perceived severity, $P S U$ perceived susceptibility, $P A$ perceived avoidability, $P E$ perceived effectiveness of COVID-19 protective measures, TI travel intention, CI 95\% confidence interval, Dif. differences, $P M I$ partial measurement invariance, $F M I$ full measurement invariance 
adjusted $R^{2}$ of perceived effectiveness of COVID-19 protective measures and travel intention were $0.231,0.104$, which is higher than the required 0.10 (Falk and Miller 1992). Also, the $Q^{2}$ value of the two constructs were 0.119 and 0.086 which is above the required threshold of 0 and implies small to medium predictive relevance (Hair et al. 2019; Hussain et al. 2018).

The results of the path analysis are presented below in Table 8. A bootstrap resampling procedure was performed to test the significance of the paths.

The results confirm the effect of perceived severity and perceived avoidability on travel intention $(\beta=-0.199, p=0.001 ; \beta=0.135, p=0.030)$. However, perceived susceptibility had no significant effect on travel intention at the $p=0.05$ level ( $\beta=-0.063, p=0.301$ ). Thus, H1(a) and H2 are supported, while H1(b) is rejected.

Analysis on the effect of risk perception on perceived effectiveness shows that perceived severity $(\beta=0.154, p=0.004)$ and perceived avoidability $(\beta=0.467$, $p=0.000$ ) significantly affect perceived effectiveness, while the effect of perceived susceptibility is non-significant $(\beta=0.026, p=0.658)$. Therefore, only H3(a) and 4 are supported.

Also, the perceived effectiveness of COVID-19 protective measures significantly affected travel intention $(\beta=0.125, p=0.039)$ and, thus, H5 is supported. Furthermore, the result of the mediation analysis confirmed that perceived effectiveness of COVID-19 protective measures mediates the relationship between perceived avoidability and travel intention $(\beta=0.058, p=0.045)$ but does not mediate the perceived severity-travel intention relation $(\beta=0.019, p=0.104)$, thus partially supporting H6.

Finally, accommodation type negatively moderated the perceived effectivenesstravel intention relation $(\beta=-0.136, p=0.008)$, meaning that individuals who prefer hotels show a stronger positive relation compared to those who prefer Airbnbs when travelling. Therefore, $\mathrm{H} 7$ is supported.

Additionally, based on the classification by Cohen (1988), most significant relations showed weak $\left(f^{2} \geq 0.02\right)$ to moderate effect size $\left(f^{2} \geq 0.15\right)$ with the exception of $\mathrm{H} 2$ and 5, which was statistically significant but had no effect.

Table 8 Results of path analysis

\begin{tabular}{|c|c|c|c|c|c|}
\hline Path & Hypotheses & Beta & $t$ value & Results & $f^{2}$ \\
\hline $\mathrm{PS} \rightarrow \mathrm{TI}$ & $\mathrm{H} 1(\mathrm{a})$ & -0.199 & 3.399 & Supported & 0.038 \\
\hline $\mathrm{PSU} \rightarrow \mathrm{TI}$ & $\mathrm{H} 1(\mathrm{~b})$ & -0.063 & 1.036 & Not supported & 0.004 \\
\hline $\mathrm{PA} \rightarrow \mathrm{TI}$ & $\mathrm{H} 2$ & 0.135 & 2.177 & Supported & 0.016 \\
\hline $\mathrm{PS} \rightarrow \mathrm{PE}$ & H3(a) & 0.154 & 2.877 & Supported & 0.027 \\
\hline $\mathrm{PSU} \rightarrow \mathrm{PE}$ & H3(b) & 0.026 & 0.443 & Not supported & 0.001 \\
\hline $\mathrm{PA} \rightarrow \mathrm{PE}$ & $\mathrm{H} 4$ & 0.467 & 10.251 & Supported & 0.278 \\
\hline $\mathrm{PE} \rightarrow \mathrm{TI}$ & H5 & 0.125 & 2.068 & Supported & 0.014 \\
\hline $\mathrm{PS} \rightarrow \mathrm{PE} \rightarrow \mathrm{TI}$ & H6 & 0.019 & 1.677 & Not supported & \\
\hline $\mathrm{PA} \rightarrow \mathrm{PE} \rightarrow \mathrm{TI}$ & H6 & 0.058 & 1.983 & Supported & \\
\hline Accommodation type & $\mathrm{H} 7$ & -0.136 & 2.668 & Supported & \\
\hline
\end{tabular}

$P S$ perceived severity, $P S U$ perceived susceptibility, $P A$ perceived avoidability, $P E$ perceived effectiveness of COVID-19 protective measures, $T I$ travel intention 


\subsection{Predictive power}

Recently, the PLS predict technique is often utilized to conduct out-of-sample predictive analysis. The PLS predict executes k-fold cross-validation to evaluate the predictive power of a certain model on data other than the training sample, also known as the holdout sample (Hair et al. 2019; Shmueli et al. 2019). According to Hair et al. (2019), if the RMSE value of the PLS-SEM analysis is higher than the naïve LM benchmark value, the model lacks predictive power. If the majority (minority) of the RMSE value of the PLS-SEM analysis is higher, the model has a low (medium) predictive power. Finally, if all the RMSE value of the PLS-SEM analysis is lower than that of the LM benchmark, the model has a high predictive power. As shown in Table 9, all the indicators show a higher RMSE value in the naïve LM benchmark analysis, indicating a high predictive power of our model.

\section{Discussion}

The results of the hypotheses testing are as follows: first, of the constructs of COVID-19 risk perception, only perceived severity and perceived avoidability affected travel intention. Specifically, while perceived severity showed weak effect size, perceived avoidability showed no effect. This is somewhat consistent with the results of prior studies that investigated the role of risk perception on travel intention or travel avoidance intention (Chua et al. 2020; Reisinger and Mavondo 2005).

Second, perceived severity and avoidability of COVID-19 positively affected the perceived effectiveness of COVID-19 protective measures. The positive impact of risk perception on perceived policy effectiveness is consistent with the results of previous studies (Kummeneje and Rundmo 2020; Prasetyo et al. 2020). Although the positive relationship between perceived severity and perceived effectiveness is rather counterintuitive, Prasetyo et al. (2020) explain that individuals with more knowledge of COVID-19 tend to exhibit higher perceived severity. However, because they understand how the virus is transmitted and how the protective measures prevent its spread, it consequently leads to higher levels of the perceived effectiveness of protective measures. Similar results and interpretations are presented in Liao et al. (2020), where individuals with additional knowledge on food safety displayed higher levels of both perceived severity and response efficacy.

Table 9 PLS predict

\begin{tabular}{|c|c|c|c|c|c|c|c|}
\hline \multirow[t]{2}{*}{ Construct } & \multirow[t]{2}{*}{ Indicators } & \multicolumn{2}{|l|}{ PLS } & \multicolumn{2}{|l|}{ LM } & \multicolumn{2}{|l|}{ PLS-LM } \\
\hline & & RMSE & $Q_{\text {predict }}^{2}$ & RMSE & $Q_{\text {predict }}^{2}$ & RMSE & $Q_{\text {predict }}^{2}$ \\
\hline \multirow[t]{3}{*}{ Travel intention } & TI1 & 0.936 & 0.017 & 0.942 & 0.005 & -0.006 & 0.012 \\
\hline & $\mathrm{TI} 2$ & 0.916 & 0.071 & 0.924 & 0.056 & -0.008 & 0.015 \\
\hline & TI3 & 0.935 & 0.065 & 0.939 & 0.056 & -0.004 & 0.009 \\
\hline
\end{tabular}


Third, the perceived effectiveness of COVID-19 protective measures positively affected travel intention. If people believe that abiding by the protective measures is beneficial in protecting them from the disease, they are more likely to engage in more risk-taking behavior, which is, in our case, travelling. For example, if they believe social distancing is effective in preventing COVID-19, they might seek travel destinations that are less crowded. This result is consistent with that of Das and Tiwari (2020). Furthermore, perceived effectiveness of COVID-19 protective measures significantly mediated the perceived avoidability-travel intention relation.

Finally, people who prefer hotels over Airbnbs showed a stronger positive relation between perceived effectiveness of COVID-19 protective measures and travelling intention, thus confirming our hypotheses regarding the moderating effect of accommodation type. Thus, it could be interpreted that people who prefer hotels are more willing to travel, under the assumption that the COVID-19 protective measures are effective.

\subsection{Theoretical implications}

Our research model and the results of the hypotheses test provide meaningful theoretical implications. First, our study confirmed that COVID-19 risk perception, specifically perceived severity, susceptibility, and avoidability, has a significant impact on travel intention. This is consistent with the result of prior studies such as McKercher and Chon (2004) and Meng et al. (2021). However, instead of treating risk perception as a single construct, our study investigated how the components of risk perception differently affect travel intention. The result showed while certain constructs affect travel intention directly, other constructs indirectly affect travel intention through perceived effectiveness of COVID-19 protective measures. Therefore, our study provides a deeper and more advanced understanding on the already established risk perception-travel intention relation.

Second, to the best of our knowledge, this is the first study in the tourism literature that investigates the role of perceived policy effectiveness, particularly in the COVID-19 context. Most studies on the topic of tourism during the pandemic simply focus on how perceived COVID-19 related risk affect the industry performance in general or individual behavior (Shin et al. 2021; Neuburger and Egger 2020). For example, prior studies have confirmed that risk, whether physical, psychological, or financial, has a negative impact on travel or revisit intention (An et al. 2010; Nik Hashim et al. 2019). Although recent studies have begun to focus on the perceived effectiveness of protective measures, most of these studies simply focus on comparing the effectiveness of different measures and none have yet studied their impact on travel intention (Nakayachi et al. 2021).

Our study expanded the result of prior studies by adopting the concept of perceived effectiveness of COVID-19 protective measures and exploring its impact on individual behavior. The results of our study argue that, as several protective measures have been adopted after the initial spread of the virus, the perceived effectiveness of these measures could mediate the negative effect of risk perception on travel intention. As the results of our path analysis shows, perceived effectiveness 
of COVID-19 protective measures not only directly affects travel intention, but also significantly mediates the relation between COVID-19 risk perception constructs and travel intention. This implies that the people's perception toward protective measures plays a crucial role in pandemic and post-pandemic individual behavior, and that future COVID-19 related research must consider this a major factor.

Finally, we adopted accommodation type, which is a widely studied factor in tourism literature (Young et al. 2017), as a moderating variable. While a few studies investigated how the pandemic has affected the hospitality industry based on accommodation type (Bresciani et al. 2021), studies utilizing it as a moderating variable is still lacking. The results of our analysis show that accommodation type is a significant moderating factor, confirming that individuals who prefer hotels show a stronger positive relation between perceived effectiveness of COVID-19 protective measures and travel intention. This approach provides a new approach to the existing literature on accommodation type and tourism. While the existing literature focused on individual attributes of accommodations (Lockyer 2005; Moliner-Velázquez et al. 2021; Pappas and Glyptou 2021), such as hygiene, safety, price, or location, our study found that, during the pandemic, external factors, such as an individual's perceived effectiveness of different policies, could act as decision-making criteria.

\subsection{Practical implications}

As the COVID-19 vaccination rate increases, an explosive increase in travel demand is anticipated. Considering the contribution of the tourism industry on national economic growth (Brida et al. 2016; Oh 2005), a strategic approach on the process of recovery from COVID-19 shock is much needed. Our study provides several practical implications for policymakers, hotel managers, Airbnb hosts, and other related stakeholders in the tourism industry.

At the outset, the results of our study confirm that controlling people's risk perception of COVID-19 is crucial to increasing travel demand. Specifically, efforts to lower the perceived severity of COVID-19 while increasing perceived avoidability are the key to increasing travel intention and recovering from pandemic shock. While the fast distribution of vaccines is expected to increase perceived avoidability in the near future, governments should also focus on filtering and correcting inaccurate information about the virus, thus reducing unnecessary fear about COVID-19.

As stated by Lăzăroiu and Adams (2020) and Marco-Franco et al. (2021), fake information about COVID-19 tends to exaggerate its risk, thus increasing the perceived severity of the disease. Therefore, controlling the spread of fake information about the disease must be preceded for the tourism industry to recover. As shown in the demographic characteristics of our study, a fairly large proportion of people obtain COVID-19-related information from social media platforms, such as YouTube. Thus, controlling the quality of information in the user generated content of social media may significantly increase travel intention.

Another strategy to increase travel intention is increasing the perceived effectiveness of COVID-19 protective measures. Perceived effectiveness not only directly affects travel intention, but also mediates the positive relationship between perceived 
avoidability and travel intention. Therefore, setting up specific guidelines providing advice on preventing COVID-19 infection during travel and how to respond if infected during travel, can help increase the perceived avoidability of the disease and the perceived effectiveness of protective measures.

Additionally, because perceived avoidability and perceived effectiveness of protective measures significantly affects travel intention, hotels and Airbnbs should focus their marketing messages on how well they adhere to COVID-19 protection guidelines, such as room sanitization or social distancing. In particular, since accommodation type negatively affected the effectiveness-travel intention relation, meaning that people who prefer hotels show a stronger positive relation, adopting hotel hygiene standards at Airbnb facilities may help increase travel demand for Airbnb hosts. For example, partnering with industrial cleaning brands to ensure the sanitization of Airbnb flats and setting up strict COVID-19 related standards may be helpful in increasing Airbnb demand during the pandemic.

\section{Conclusion and limitations}

This study aimed to identify how risk perception affects travel intention during the COVID-19 pandemic and how the perceived effectiveness of COVID-19 protective measures could mediate this relationship. Furthermore, we investigated how accommodation type moderates the perceived effectiveness-travel intention relation, thus providing helpful implications. The results of our study show that while perceived severity and avoidability directly affect travel intention, perceived susceptibility does not show a direct significant effect. Furthermore, the perceived effectiveness of COVID-19 protective measures also positively affects travel intention, while mediating the relationship between perceived avoidability and travel intention. Finally, a significant difference in the perceived effectiveness-travel intention relation between the hotel group and the Airbnb group was observed, thus supporting the claim that accommodation type is a crucial moderator during the pandemic when studying individual behavior in the tourism context.

Although our study provides meaningful managerial and practical implications, it still has some limitations. First, since this survey was only conducted in South Korea, the results of our research model may differ in other countries. Since government policies, infection rates, and vaccination rates differ greatly between countries, the effects of both risk perception and perceived policy effectiveness on travel intention may be inconsistent. Therefore, a cross-cultural examination could provide a more general and detailed understanding on the topic. Second, while our study considered travel intention as a single construct, people may have different perceptions toward domestic and international travel. Therefore, a comparison of how these behavioral intentions are affected differently could also provide more detailed implications. Finally, because a global threat such as the COVID-19 pandemic is an unprecedented event, literature reviews supporting our hypotheses are rather lacking. However, as one of the first studies focusing on the topic of tourism recovery in the post-pandemic era, we believe our study may act as a foundation for future research. 


\section{References}

An M, Lee C, Noh Y (2010) Risk factors at the travel destination: their impact on air travel satisfaction and repurchase intention. Serv Bus 4(2):155-166. https://doi.org/10.1007/s11628-010-0094-2

Assaf A, Scuderi R (2020) COVID-19 and the recovery of the tourism industry. Tour Econ 26(5):731733. https://doi.org/10.1177/1354816620933712

Bakar NA, Rosbi S (2020) Effect of Coronavirus disease (COVID-19) to tourism industry. Int J Adv Eng Res Sci 7(4):189-193. https://doi.org/10.22161/ijaers.74.23

Banks MS, Onita CG, Meservy TO (2010) Risky behavior in online social media: protection motivation and social influence. AMCIS 2010 Proceedings: 372. https://aisel.aisnet.org/amcis2010/372. Accessed 20 Mar 2021.

Bashirian S, Jenabi E, Khazaei S, Barati M, Karimi-Shahanjarini A, Zareian S, Rezapur-Shahkolai F, Moeini B (2020) Factors associated with preventive behaviours of COVID-19 among hospital staff in Iran in 2020: an application of the protection motivation theory. J Hosp Infect 105(3):430-433. https://doi.org/10.1016/j.jhin.2020.04.035

Birinci H, Berezina K, Cobanoglu C (2018) Comparing customer perceptions of hotel and peer-to-peer accommodation advantages and disadvantages. Int J Contemp Hosp Manag 30(2):1190-1210. https://doi.org/10.1108/IJCHM-09-2016-0506

Bresciani S, Ferraris A, Santoro G, Premazzi K, Quaglia R, Yahiaoui D, Viglia G (2021) The seven lives of Airbnb. The role of accommodation types. Ann Tour Res 88:100. https://doi.org/10.1016/j. annals.2021.103170

Brewer NT, Chapman GB, Gibbons FX, Gerrard M, McCaul KD, Weinstein ND (2007) Meta-analysis of the relationship between risk perception and health behavior: the example of vaccination. Health Psychol 26(2):136. https://doi.org/10.1037/0278-6133.26.2.136

Brida JG, Cortes-Jimenez I, Pulina M (2016) Has the tourism-led growth hypothesis been validated? A literature review. Curr Issue Tour 19(5):394-430. https://doi.org/10.1080/13683500.2013.868414

Cauberghe V, De Pelsmacker P, Janssens W, Dens N (2009) Fear, threat and efficacy in threat appeals: message involvement as a key mediator to message acceptance. Accid Anal Prev 41(2):276-285. https://doi.org/10.1016/j.aap.2008.11.006

Chan APH, Tung VWS (2019) Examining the effects of robotic service on brand experience: the moderating role of hotel segment. J Travel Tour Mark 36(4):458-468. https://doi.org/10.1080/10548408. 2019.1568953

Chatterjee R, Bajwa S, Dwivedi D, Kanji R, Ahammed M, Shaw R (2020) COVID-19 risk assessment tool: dual application of risk communication and risk governance. Prog Disaster Sci 7:100109. https://doi.org/10.1016/j.pdisas.2020.100109

Cheah JH, Sarstedt M, Ringle CM, Ramayah T, Ting H (2018) Convergent validity assessment of formatively measured constructs in PLS-SEM: on using single-item versus multi-item measures in redundancy analyses. Int J Contemp Hosp Manag 30(11):3192-3210. https://doi.org/10.1108/ IJCHM-10-2017-0649

Cheng M, Jin X (2019) What do Airbnb users care about? An analysis of online review comments. Int J Hosp Manag 76:58-70. https://doi.org/10.1016/j.ijhm.2018.04.004

Chew EYT, Jahari SA (2014) Destination image as a mediator between perceived risks and revisit intention: a case of post-disaster Japan. Tour Manag 40:382-393. https://doi.org/10.1016/j.tourman. 2013.07.008

Chua BL, Al-Ansi A, Lee MJ, Han H (2020) Impact of health risk perception on avoidance of international travel in the wake of a pandemic. Curr Issue Tour 24(7):985-1002. https://doi.org/10.1080/ 13683500.2020 .1829570

Cohen J (1988) Statistical power analysis for the behavioral sciences, 2nd edn. Erlbaum, Hillsdale

Cori L, Bianchi F, Cadum E, Anthonj C (2020) Risk perception and COVID-19. Int J Environ Res Public Health 17(9):3114. https://doi.org/10.3390/ijerph17093114

Coshall JT (2003) The threat of terrorism as an intervention on international travel flows. J Travel Res 42(1):4-12. https://doi.org/10.1177/0047287503253901

Das SS, Tiwari AK (2020) Understanding international and domestic travel intention of Indian travellers during COVID-19 using a Bayesian approach. Tour Recreat Res 46(2):228-244. https://doi.org/10. 1080/02508281.2020.1830341 
Diamantopoulos A, Siguaw JA (2006) Formative versus reflective indicators in organizational measure development: a comparison and empirical illustration. Br J Manag 17(4):263-282. https://doi.org/ 10.1111/j.1467-8551.2006.00500.x

Doornekamp L, van Leeuwen L, van Gorp E, Voeten H, Goeijenbier M (2020) Determinants of vaccination uptake in risk populations: a comprehensive literature review. Vaccines 8(3):480. https://doi. org/10.3390/vaccines 8030480

Ezati Rad R, Mohseni S, Kamalzadeh Takhti H et al (2021) Application of the protection motivation theory for predicting COVID-19 preventive behaviors in Hormozgan, Iran: a cross-sectional study. BMC Public Health 21:446. https://doi.org/10.1186/s12889-021-10500-w

Falk RF, Miller NB (1992) A primer for soft modeling. University of Akron Press, Akron

Floyd DL, Prentice-Dunn S, Rogers RW (2000) A meta-analysis of research on protection motivation theory. J Appl Soc Psychol 30(2):407-429. https://doi.org/10.1111/j.1559-1816.2000.tb02323.x

Floyd MF, Gibson H, Pennington-Gray L, Thapa B (2004) The effect of risk perceptions on intentions to travel in the aftermath of September 11, 2001. J Travel Tour Mark 15(2-3):19-38. https://doi.org/ 10.1300/J073v15n02_02

Fornell C, Larcker DF (1981) Evaluating structural equation models with unobservable variables and measurement error. J Mark Res 18(1):39-50. https://doi.org/10.2307/3151312

Franzen A, Wöhner F (2021) Coronavirus risk perception and compliance with social distancing measures in a sample of young adults: evidence from Switzerland. PLoS ONE 16(2):e0247447. https:// doi.org/10.1371/journal.pone.0247447

Hair JF, Matthews LM, Matthews RL, Sarstedt M (2017) PLS-SEM or CB-SEM: updated guidelines on which method to use. Int J Multivar Data Anal 1(2):107-123. https://doi.org/10.1504/IJMDA.2017. 087624

Hair JF, Risher JJ, Sarstedt M, Ringle CM (2019) When to use and how to report the results of PLS-SEM. Eur Bus Rev 31(1):2-24. https://doi.org/10.1108/EBR-11-2018-0203

Hair JF, Hult GTM, Ringle CM, Sarstedt M (2021) A primer on partial least squares structural equation modeling (PLS-SEM), 2nd edn. Sage Publications, Los Angeles

Hakim MP, Zanetta LDA, da Cunha DT (2021) Should I stay, or should I go? Consumers' perceived risk and intention to visit restaurants during the COVID-19 pandemic in Brazil. Food Res Int 141:110152

Hassan SH, Ramayah T, Mohamed O, Maghsoudi A (2015) E-Lifestyle conceptualization: measurement model validation using variance based structural equation modeling (SEM-PLS). Mod Appl Sci 9(2):307-319. https://doi.org/10.5539/mas.v9n2p307

Henseler J, Ringle CM, Sarstedt M (2016) Testing measurement invariance of composites using partial least squares. Int Mark Rev 33(3):405-431. https://doi.org/10.1108/IMR-09-2014-0304

Hoang TG, Truong NT, Nguyen TM (2021) The survival of hotels during the COVID-19 pandemic: a critical case study in Vietnam. Serv Bus 15(2):209-229. https://doi.org/10.1007/s11628-021-00441-0

Hussain S, Fangwei Z, Siddiqi AF, Ali Z, Shabbir MS (2018) Structural equation model for evaluating factors affecting quality of social infrastructure projects. Sustainability 10(5):1415. https://doi.org/ $10.3390 /$ su 10051415

Katapodi MC, Dodd MJ, Lee KA, Facione NC (2009) Underestimation of breast cancer risk: influence on screening behavior. Oncol Nurs Forum 36(3):306-314. https://doi.org/10.1188/09.onf.306-314

Kummeneje AM, Rundmo T (2020) Attitudes, risk perception and risk-taking behaviour among regular cyclists in Norway. Transp Res F: Traffic Psychol Behav 69:135-150. https://doi.org/10.1016/j.trf. 2020.01.007

Lăzăroiu G, Adams C (2020) Viral panic and contagious fear in scary times: the proliferation of COVID19 misinformation and fake news. Anal Metaphys 19:80-86. https://doi.org/10.22381/AM1920209

Lee CK, Song HJ, Bendle LJ, Kim MJ, Han H (2012) The impact of non-pharmaceutical interventions for $2009 \mathrm{H} 1 \mathrm{~N} 1$ influenza on travel intentions: a model of goal-directed behavior. Tour Manage 33(1):89-99. https://doi.org/10.1016/j.tourman.2011.02.006

Liang H, Xue Y (2009) Avoidance of information technology threats: a theoretical perspective. MIS Q 33(1):71-90. https://doi.org/10.2307/20650279

Liang H, Xue Y, Pinsonneault A, Wu Y (2019) What users do besides problem-focused coping when facing it security threats: an emotion-focused coping perspective. MISQ 43(2):373-394. https://doi. org/10.25300/MISQ/2019/14360

Liao C, Yu H, Zhu W (2020) Perceived knowledge, coping efficacy and consumer consumption changes in response to food recall. Sustainability 12(7):2696. https://doi.org/10.3390/su12072696 
Lockyer T (2005) Understanding the dynamics of the hotel accommodation purchase decision. Int J Contemp Hosp Manag 17(6):481-492. https://doi.org/10.1108/09596110510612121

Long NN, Khoi BH (2020) An empirical study about the intention to hoard food during COVID-19 pandemic. Eurasia J Math, Sci Technol Educ 16(7):1857. https://doi.org/10.29333/ejmste/8207

Luo Y, Cheng Y, Sui M (2021) The moderating effects of perceived severity on the generational gap in preventive behaviors during the COVID-19 pandemic in the US. Int J Environ Res Public Health 18(4):2011. https://doi.org/10.3390/ijerph18042011

Marco-Franco JE, Pita-Barros P, Vivas-Orts D, González-de-Julián S, Vivas-Consuelo D (2021) COVID19, fake news, and vaccines: should regulation be implemented? Int J Environ Res Public Health 18(2):744. https://doi.org/10.3390/ijerph18020744

Margraf J, Brailovskaia J, Schneider S (2021) Adherence to behavioral Covid-19 mitigation measures strongly predicts mortality. PLoS ONE 16(3):e0249392. https://doi.org/10.1371/journal.pone.02493 92

McKercher B, Chon K (2004) The over-reaction to SARS and the collapse of Asian tourism. Ann Tour Res 31(3):716. https://doi.org/10.1016/j.annals.2003.11.002

Meier K, Glatz T, Guijt MC, Piccininni M, Van Der Meulen M, Atmar K et al (2020) Public perspectives on protective measures during the COVID-19 pandemic in the Netherlands, Germany and Italy: a survey study. PLoS ONE 15(8):e0236917. https://doi.org/10.1371/journal.pone.0236917

Meng Y, Khan A, Bibi S, Zhao W, Chen W, Lee Y (2021) The effects of COVID-19 risk perception on travel intention: evidence from Chinese travelers. Front Psychol 12:655860. https://doi.org/10.3389/ fpsyg.2021.655860

Michie S, Van Stralen MM, West R (2011) The behaviour change wheel: a new method for characterising and designing behaviour change interventions. Implement Sci 6(1):1-12. https://doi.org/10.1186/ 1748-5908-6-42

Moliner-Velázquez B, Fuentes-Blasco M, Gil-Saura I (2021) Segmenting customers according to online word-of-mouth about hotels. Serv Bus 15(1):103-130. https://doi.org/10.1007/s11628-020-00435-4

Nakayachi K, Ozaki T, Shibata Y, Yokoi R (2021) A comparison of perceived effectiveness of preventive behaviors against COVID-19 between the public and medical experts: not so different in means, but in distributions. J Health Psychol. https://doi.org/10.1177/1359105321999701

Nazir MU, Yasin I, Tat HH (2021) Destination image's mediating role between perceived risks, perceived constraints, and behavioral intention. Heliyon 7(7):e07613. https://doi.org/10.1016/j.heliyon.2021. e07613

Neuburger L, Egger R (2020) Travel risk perception and travel behaviour during the COVID-19 pandemic 2020: a case study of the DACH region. Curr Issue Tour 24(7):1003-1016. https://doi.org/10. 1080/13683500.2020.1803807

Nik Hashim N, Yusoff AM, Awang Z, Aziz RC, Ramlee SIF, Bakar NA, Fatt BS (2019) The effect of domestic tourist perceived risk on revisit intention in Malaysia. IJITEE 8(10):4591-4596. https:// doi.org/10.35940/ijitee.J1085.0881019

Oh CO (2005) The contribution of tourism development to economic growth in the Korean economy. Tour Manag 26(1):39-44. https://doi.org/10.1016/j.tourman.2003.09.014

Pappas N, Glyptou K (2021) Accommodation decision-making during the COVID-19 pandemic: complexity insights from Greece. Int J Hosp Manag 93:102767. https://doi.org/10.1016/j.ijhm.2020. 102767

Prasetyo YT, Castillo AM, Salonga LJ, Sia JA, Seneta JA (2020) Factors affecting perceived effectiveness of COVID-19 prevention measures among Filipinos during enhanced community quarantine in Luzon, Philippines: integrating protection motivation theory and extended theory of planned behavior. Int J Infect Dis 99:312-323. https://doi.org/10.1016/j.ijid.2020.07.074

Reisinger Y, Mavondo F (2005) Travel anxiety and intentions to travel internationally: implications of travel risk perception. J Travel Res 43(3):212-225. https://doi.org/10.1177/0047287504272017

Reinartz W, Haenlein M, Henseler J (2009) An empirical comparison ofthe efficacy of covariance-based and variance-based SEM. International Journal of research in Marketing 26(4): 332-344. https://doi. org/10.1016/j.ijresmar.2009.08.001

Romer D, Jamieson P (2001) Do adolescents appreciate the risks of smoking? Evidence from a national survey. J Adolesc Health 29(1):12-21. https://doi.org/10.1016/s1054-139x(01)00209-9

Safón V, Escribá-Esteve A (2011) Antecedents and consequences of external risk perception in franchising: evidence from the hospitality industry. Serv Bus 5(3):237. https://doi.org/10.1007/ s11628-011-0112-Z 
Schneider A, Ingram H (1990) Behavioral assumptions of policy tools. J Politics 52(2):510-529. https:// doi.org/10.2307/2131904

Shin Y, Hur WM, Hwang H (2021) Impacts of customer incivility and abusive supervision on employee performance: a comparative study of the pre-and post-COVID-19 periods. Serv Bus. https://doi.org/ 10.1007/s11628-021-00456-7

Shmueli G, Sarstedt M, Hair JF, Cheah JH, Ting H, Vaithilingam S, Ringle CM (2019) Predictive model assessment in PLS-SEM: guidelines for using PLSpredict. Eur J Mark 53(11):2322-2347. https:// doi.org/10.1108/EJM-02-2019-0189

Song S, Suess C, Mody MA, Dogru T (2020) Comparing the influence of substantive and communicative servicescape on healthcare traveler emotions: the moderating effect of accommodation type and interior design style. Int J Contemp Hosp Manag 33(1):1-26. https://doi.org/10.1108/ IJCHM-12-2019-1022

Sönmez SF, Graefe AR (1998) Determining future travel behavior from past travel experience and perceptions of risk and safety. J Travel Res 37(2):171-177. https://doi.org/10.1177/004728759803700 209

Uğur NG, Akbıyık A (2020) Impacts of COVID-19 on global tourism industry: a cross-regional comparison. Tour Manag Perspect 36:100744. https://doi.org/10.1016/j.tmp.2020.100744

Vacondio M, Priolo G, Dickert S, Bonini N (2021) Worry, perceived threat and media communication as predictors of self-protective behaviors during the COVID-19 outbreak in Europe. Front Psychol 12:231. https://doi.org/10.3389/fpsyg.2021.577992

Wan C, Shen GQ, Yu A (2014) The role of perceived effectiveness of policy measures in predicting recycling behaviour in Hong Kong. Resour Conserv Recycl 83:141-151. https://doi.org/10.1016/j.resco nrec.2013.12.009

World Tourism Organization (UNWTO) (2021) COVID-19 and Tourism 2020: a year in review. https:// www.unwto.org/covid-19-and-tourism-2020. Accessed 12 Mar 2021.

Yan R, Zhang KZ, Yu Y (2019) Switching from hotels to peer-to-peer accommodation: an empirical study. Inf Technol People 32(6):1657-1678. https://doi.org/10.1108/ITP-12-2017-0444

Yavas U, Babakus E (2005) Dimensions of hotel choice criteria: congruence between business and leisure travelers. Int J Hosp Manag 24(3):359-367. https://doi.org/10.1016/j.ijhm.2004.09.003

Young CA, Corsun DL, Xie KL (2017) Travelers' preferences for peer-to-peer (P2P) accommodations and hotels. IJCTHR 11(4):465-482. https://doi.org/10.1108/IJCTHR-09-2016-0093

Zeballos Rivas DR, Lopez Jaldin ML, Nina Canaviri B, Portugal Escalante LF, Alanes Fernández AM, Aguilar Ticona JP (2021) Social media exposure, risk perception, preventive behaviors and attitudes during the COVID-19 epidemic in La Paz, Bolivia: a cross sectional study. PLoS ONE 16(1):859. https://doi.org/10.1371/journal.pone.0245859

Zhang H, Song H, Wen L, Liu C (2021) Forecasting tourism recovery amid COVID-19. Ann Tour Res 87:103149. https://doi.org/10.1016/j.annals.2021.103149

Zhu W, Wei J, Zhao D (2016) Anti-nuclear behavioral intentions: the role of perceived knowledge, information processing, and risk perception. Energy Policy 88:168-177. https://doi.org/10.1016/j.enpol. 2015.10.009

Publisher's Note Springer Nature remains neutral with regard to jurisdictional claims in published maps and institutional affiliations. 